\title{
Current therapeutic applications and pharmacokinetic modulations of ivermectin
}

\author{
Khan Sharun ${ }^{1}$, T. S. Shyamkumar ${ }^{2}$, V. A. Aneesha른 Kuldeep Dhama ${ }^{3}$, Abhijit Motiram Pawde ${ }^{1}$ and Amar Pal ${ }^{1}$ \\ 1. Division of Surgery, ICAR-Indian Veterinary Research Institute, Bareilly, Uttar Pradesh, India; 2. Division of \\ Pharmacology and Toxicology, ICAR-Indian Veterinary Research Institute, Bareilly, Uttar Pradesh, India; 3. Division of \\ Pathology, ICAR-Indian Veterinary Research Institute, Bareilly, Uttar Pradesh, India. \\ Corresponding author: Khan Sharun, e-mail: sharunkhansk@gmail.com \\ Co-authors: TSS: shyamkumartscovas@gmail.com, VAA: draneeshava@gmail.com, KD: kdhama@rediffmail.com, \\ AMP: abhimp@rediffmail.com, AP: dramarpal@gmail.com \\ Received: 17-05-2019, Accepted: 29-06-2019, Published online: 08-08-2019
}

doi: 10.14202/vetworld.2019.1204-1211 How to cite this article: Sharun K, Shyamkumar TS, Aneesha VA, Dhama K, Pawde AM, Pal A (2019) Current therapeutic applications and pharmacokinetic modulations of ivermectin, Veterinary World, 12(8): 1204-1211.

\begin{abstract}
Ivermectin is considered to be a wonder drug due to its broad-spectrum antiparasitic activity against both ectoparasites and endoparasites (under class of endectocide) and has multiple applications in both veterinary and human medicine. In particular, ivermectin is commonly used in the treatment of different kinds of infections and infestations. By altering the vehicles used in the formulations, the pharmacokinetic properties of different ivermectin preparations can be altered. Since its development, various vehicles have been evaluated to assess the efficacy, safety, and therapeutic systemic concentrations of ivermectin in different species. A subcutaneous route of administration is preferred over a topical or an oral route for ivermectin due to superior bioavailability. Different formulations of ivermectin have been developed over the years, such as stabilized aqueous formulations, osmotic pumps, controlled release capsules, silicone carriers, zein microspheres, biodegradable microparticulate drug delivery systems, lipid nanocapsules, solid lipid nanoparticles, sustained-release ivermectin varnish, sustained-release ivermectin-loaded solid dispersion suspension, and biodegradable subcutaneous implants. However, several reports of ivermectin resistance have been identified in different parts of the world over the past few years. Continuous use of suboptimal formulations or sub-therapeutic plasma concentrations may predispose an individual to resistance toward ivermectin. The current research trend is focused toward the need for developing ivermectin formulations that are stable, effective, and safe and that reduce the number of doses required for complete clinical cure in different parasitic diseases. Therefore, single-dose long-acting preparations of ivermectin that provide effective therapeutic drug concentrations need to be developed and commercialized, which may revolutionize drug therapy and prophylaxis against various parasitic diseases in the near future. The present review highlights the current advances in pharmacokinetic modulation of ivermectin formulations and their potent therapeutic applications, issues related to emergence of ivermectin resistance, and future trends of ivermectin usage.
\end{abstract}

Keywords: ivermectin, ivermectin resistance, pharmacokinetic modulation, therapeutic applications.

\section{Introduction}

Ivermectin is a macrocyclic lactone obtained from the actinomycete, Streptomyces avermitilis [1]. It was the first macrocytic lactone anthelmintic to be introduced into veterinary use and is also the most widely used endectocide in animals [2]. It is considered a wonder drug, primarily due to its broad-spectrum antiparasitic activity against both ectoparasites and endoparasites in veterinary and human medicine. The activity spectrum of ivermectin is expanding every year making it one of the most useful drugs ever discovered.

Even though various antiparasitic drugs have lost their importance as therapeutic agents in managing parasitic diseases, ivermectin has been a popular

Copyright: Sharun, et al. Open Access. This article is distributed under the terms of the Creative Commons Attribution 4.0 International License (http://creativecommons.org/licenses/ by/4.0/), which permits unrestricted use, distribution, and reproduction in any medium, provided you give appropriate credit to the original author(s) and the source, provide a link to the Creative Commons license, and indicate if changes were made. The Creative Commons Public Domain Dedication waiver (http:// creativecommons.org/publicdomain/zero/1.0/) applies to the data made available in this article, unless otherwise stated. drug of choice for the treatment of various parasitic diseases in humans and animals. Its mode of action includes opening of the glutamate-gated and gamma-aminobutyric acid-gated chloride channels, especially in invertebrates, thereby increasing the conductance of chloride ions leading to an increase in chloride transmission, which causes motor paralysis in parasites [3]. In a recent study, ivermectin was shown to potentiate glutamate-gated chloride channel receptors in invertebrate synapses by enhancing the amplitude of synaptic current and decay time. The study evaluated the glutamate-gated chloride channel receptors in the endoparasite Haemonchus contortus [4]. The characteristic feature of ivermectin is that its pharmacokinetic properties can be modified by altering the type of formulation [5]. The vehicle used in the pharmaceutical formulations of ivermectin plays an important role in absorption of drug from the injection site and thereby, its bioavailability [2].

The present review aimed to analyze the different pharmacokinetic modifications of ivermectin formulations that have been developed and utilized to ensure the wide spectrum activity of this drug in managing 
different parasitic diseases in veterinary and human medicine. Issues related to emergence of ivermectin resistance have also been presented.

\section{Therapeutic Applications Of Ivermectin}

Since the development of ivermectin, it has been used to treat various diseases caused by ectoparasites and endoparasites in humans and other animals. However, ivermectin shows limited effectiveness against trematodes or cestodes [6]. It has high efficacy in the control of ectoparasites, such as fleas, flies, ticks, and mites that significantly affect weight gain and milk production in animals [7]. Ivermectin is administered on a monthly basis in canines as a prophylactic agent in controlling heartworm infection caused by Dirofilaria immitis [8].

Ivermectin is also considered to be a safe therapeutic agent in human medicine, mainly in managing onchocerciasis. Furthermore, it is used as an effective microfilaricide at the recommended single dose of $150 \mu \mathrm{g} / \mathrm{kg}$ for up to 1 year [9]. It is also effective in eliminating microfilaria, Wuchereria bancrofti and Brugia malayi in humans [10]. Glaziou et al. reported that ivermectin is effective in treating head lice (Pediculus capitis) in human patients [11]. In a therapeutic trial conducted using oral ivermectin against human intestinal nematodes, it was found that this drug is effective against strongyloidiasis, ascariasis, trichuriasis, and enterobiasis [12]. Topical ivermectin preparation has been used for the safe and effective treatment of papulopustular rosacea (PPR) in humans [13]. PPR is a chronic cutaneous disorder characterized by persistent facial erythema and transient papules or pustules [14]. Recently, ivermectin gained importance as a new method of controlling malaria transmission in humans by targeting the zoophagic behavior of Anopheles mosquito that is responsible for its transmission. Administration of ivermectin in livestock was also found to be useful in tackling malaria transmission in humans by zoophagic vectors. Silicone-based slow release ivermectin implants when inserted in cattle caused mortality among the anopheles mosquito that feeds on the blood of cattle [15]. More recent applications of ivermectin are described in Figure-1 [16-24].

\section{Impact Of Ivermectin Formulations On Its Pharmacokinetics}

Pharmacokinetic parameters of ivermectin are influenced by various factors which include species, route of administration, vehicle used in the drug formulation, body weight, body condition, physiological status, and the nutritional status of the animal [25]. The most important factors that affect the bioavailability and duration of action of different ivermectin preparations include the route of administration and the type of formulations. Ivermectin is generally insoluble and unstable in aqueous preparations. Hence, to overcome the problem of poor water solubility and obtain a stable injectable formulation of ivermectin, several commercial preparations have been developed which use organic solvents as vehicles. However, high concentrations of organic solvents have been reported to induce significant side effects in many species [26]. Frosch reported that pain and inflammation at the injection site were commonly observed side effects of commercial ivermectin preparations [27]. The commercially available ivermectin preparations employ different

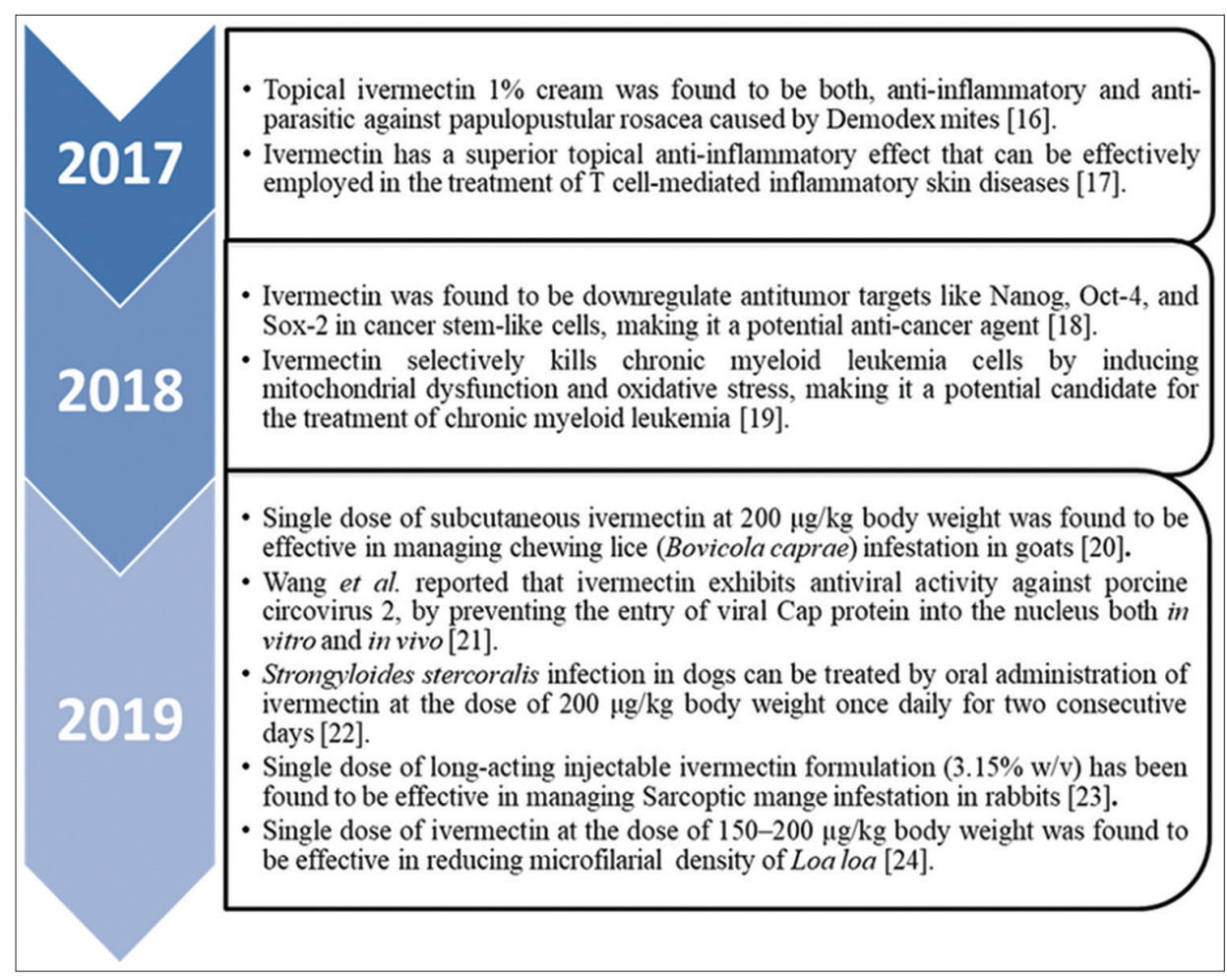

Figure-1: Chart representing the recent findings that extend the activity spectrum of ivermectin [16-24]. 
vehicles that help in stabilizing the compound. It has been reported that the bioavailability of ivermectin varies according to the nature of vehicle [28]. Lifschitz et al. reported major differences in the pharmacokinetics of ivermectin in different generic preparations. These differences were significantly high with respect to the pattern of absorption from the site of injection and efficacy of the formulation as an antiparasitic agent [29]. Different formulations have been developed that facilitate different routes of administration and enable the development of different combinations with other antiparasitic drugs [30]. A time-dependent increase in the uptake of ivermectin was induced by oleic acid-containing complex micelles in an in vitro study conducted in Caco-2 cells [31]. In this study, oleic acid was found to be an efficient vehicle for ivermectin due to its ability to enhance the solubility and transport by reducing the p-glycoprotein (P-gp)-mediated efflux of ivermectin. The composition of various formulations of ivermectin and their characteristic features is described in Table-1 [7,26,28,32-61]. Vehicles, such as oils, liposomes, and other microparticles, can reduce drug metabolism and can enhance the release of large quantities of the active form of the drug over a long period of time to the target site by altering its pharmacokinetics [62].

Compared to the oral and topical application of ivermectin formulations, the subcutaneous route has been observed to be the most efficient route of administration in terms of bioavailability [63]. Following subcutaneous administration of ivermectin, the rate of absorption from the site of deposition and the rate of distribution and elimination of the drug were also found to be low [64]. Oral administration of ivermectin has relatively lower bioavailability due to binding of the drug with organic contents in the gut. In a study conducted in cattle, it was found that a large percentage of the orally administered ivermectin is excreted in feces [65].

Due to the immense potential of pharmacokinetic modulation of drug delivery for ivermectin, several formulations have been developed over the years that include stabilized aqueous formulations, osmotic pumps, controlled-release capsule, silicone carriers, zein microspheres, biodegradable microparticulate drug delivery systems, and biodegradable subcutaneous implants [32-35,38,40,48]. Several sustained-release formulations such as sustained-release ivermectin varnish and sustained-release ivermectin-loaded solid dispersion suspension were also developed during this period $[7,44,46,53]$. Advanced nanotechnology has also contributed to the development of formulations such as lipid nanocapsules and solid lipid nanoparticles that were found to be effective in modifying the pharmacokinetics of ivermectin $[52,54]$.

\section{Emergence of Ivermectin Resistance}

Ivermectin resistance has emerged as a major problem that limits its therapeutic uses. The mechanism of ivermectin resistance has not yet been established even though multiple hypotheses have been put forward by different researchers. Atif et al. reported that incorporation of endogenous ivermectin-insensitive subunits in the glutamate-gated chloride channel receptors in the synapses of the endoparasite $H$. contortus attenuated ivermectin action [66]. The G36A mutation that affects the third transmembrane domain of glutamate-gated chloride channel receptor was found to affect ivermectin sensitivity by decreasing the active period duration, thereby increasing receptor desensitization [4]. Genomic analysis of the ivermectin-resistant and sensitive isolates of the nematode $H$. contortus revealed that a single quantitative trait locus found on chromosome V was found to be linked with ivermectin resistance [67]. Shoop (1993) reported that most cases of ivermectin resistance resulted from the intensive use of ivermectin over several years [68].

Ivermectin resistance is detected by analysis of drug efficacy using methods such as post-mortem worm counts, nematode egg-count reduction, and in vitro assays for the development of immature stages of nematodes [69]. Lekimme et al. reported that the use of suboptimal formulations of ivermectin, such as pour-on and sustained release bolus products may cause emergence of resistance in Psoroptic mites [70]. Use of pour-on formulations of ivermectin results in relatively reduced bioavailability of this drug in horses. Such sub-therapeutic plasma concentrations of ivermectin may result in the development of drug resistance in parasites [2]. Xu et al. provided evidence that ivermectin resistance in nematodes can also be caused by alterations in P-gp and also pointed out that changes in P-gp in drug selected strains may contribute to ivermectin resistance in vivo [69]. Ivermectin resistance has also been reported in canine heartworm and $D$. immitis [71]. Ivermectin insensitivity is a major source of concern in intestinal infections by nematodes in goats, sheep, and cattle, which have a long history of intensive and long-term treatment with ivermectin [72]. Currie et al. reported the emergence of ivermectin resistance in Sarcoptes scabiei in patients treated with ivermectin for several years [73]. This projects the need for accurate and precise delivery of ivermectin into the systemic circulation, the failure of which is likely to result in the emergence of ivermectin resistance. At present, combination therapy is gaining popularity in the management of diseases that are resistant to conventional drugs. Ivermectin is combined with different therapeutic agents for improving the spectrum of activity against such parasitic diseases. Tribendimidine-ivermectin has been found to be a promising drug combination for the treatment of soil-transmitted helminthic infections [74].

\section{Conclusion and Future Prospects}

In recent years, multiple efforts have been directed toward the development of long-acting 
Table-1: Different vehicles used in various ivermectin formulations in animals.

Composition of the formulation

Stabilized aqueous formulation containing $0.1-7.5 \% \mathrm{w} / \mathrm{v}$

ivermectin (Parenteral administration) with other components such as surface active agent $-0.5-2.5 \%$ (polyoxyethylene sorbitan monoisostearate, polyoxyethylene sorbitan monostearate, and polysorbate 80 ). Cosolvent - 10-60\% (glycerol formal, glycerin, and polyethylene glycol) and Substrate - 1-5\% w/v (benzyl alcohol, lidocaine, parabens, and choline)

Oral administration of bolus containing ivermectin which is released by an osmotic pump

Controlled release capsule administered orally using a specially designed balling gun which is formulated to deliver ivermectin for approximately 100 days at the rate of $1.6 \mathrm{mg} /$ day

Ivermectin is delivered using intraluminal controlled-release capsule Subcutaneous and intramuscular administration of a novel oil-based formulation of ivermectin was found to be superior to the commercially available standard preparation

Formulation using silicone as a carrier that releases ivermectin over a long period of time. The lateral side of a cylindrical matrix-type formulation composed of ivermectin and silicone was used to produce a CR formulation

Subcutaneous administration of ivermectin-loaded Poly ( $D$,

L-lactic-co-glycolic) acid microparticles was found to be an effective long-term ivermectin formulation

Zein microspheres $600 \mathrm{mg}$ zein (plant protein isolated from corn) and 60 $\mathrm{mg}$ ivermectin were dissolved in $12 \mathrm{ml}$ ethanol (66.7\%). To this, $8 \mathrm{ml}$ of ultrapure Milli-Q water was added and mixed using an agitator and tableted microspheres (Compressing 220 mg of microspheres containing ivermectin using a mold) were used for sustained-release of ivermectin Ivermectin was dissolved in a mixture of propylene glycol and glycerol formal at a ratio of $60: 40 \mathrm{v} / \mathrm{v}$ that also contains $5 \%$ polyvinylpyrrolidone Subcutaneous administration of ivermectin containing multilamellar liposomal vesicles made by distearoylphosphatidylcholine, cholesterol, and distearoylphosphatidyl-ethanolamine-polyethylene glycol5000 (DSPE-PEG5000) at the molar ratio of 1.85:1:0.15, respectively

Intravenous administration of ivermectin formulation containing propylene glycol: glycerol formal $(60: 40 \mathrm{v} / \mathrm{v})$ containing $5 \%$

polyvinylpyrrolidone

Commercially available ivermectin (3.15\%) long-acting

preparations (Ivomec Gold ${ }^{\circledR}$, Merial) showed extended absorption process and long systemic persistence

Sustained release solid dispersion was prepared by mixing ivermectin and hydrogenated castor oil which were further suspended in water to make an aqueous suspension that can be given subcutaneously Topical ivermectin formulations containing $1,0.5$, and $0.25 \%$ ivermectin were used that contains deionized water, olive oil USP, surfactants, shea butter, sorbitan tristearate, methylparaben, and propylparaben

Ivermectin-loaded poly (lactide-co-glycolide) and poly ( $D$, L-lactide) based microparticles were produced, which were used as sustained release parenteral ivermectin formulation

In situ forming implants that acted as sustained-release formulation of ivermectin were prepared from biodegradable polymers

such as poly ( $D$, L-lactide) and biocompatible solvents such as

$\mathrm{N}$-methyl-2-pyrrolidone, 2-pyrrolidone, triacetin, and benzyl benzoate Fast-dissolving oral films containing ivermectin were administered orally. This method of oral drug delivery was found to be effective for long-term studies

Sterile biodegradable microparticulate drug delivery systems containing ivermectin which are based on PLA and PCL that can be used for subcutaneous administration

Whole-body bathing method was used to deliver ivermectin to the skin without entering the plasma. The bath fluid contained ivermectin at a concentration of $100 \mathrm{ng} / \mathrm{ml}$. This was found to be a more effective drug delivery system for the skin

Implant (silicone-CR formulation) is made up of two concentric silicone cylinders. The outer cylinder is a silicone impermeable membrane and the inner cylinder contains silicone along with a mixture of ivermectin, deoxycholate sodium, and sucrose

\begin{tabular}{lll}
$\begin{array}{l}\text { Route of } \\
\text { administration }\end{array}$ & $\begin{array}{l}\text { Animal } \\
\text { understudy }\end{array}$ & References \\
\hline
\end{tabular}

Parenteral and -

Oral

$\begin{array}{ll}\text { Oral } & \text { Cattle } \\ \text { Oral } & \text { Sheep } \\ & \\ \text { Intraluminal } & \text { Sheep } \\ \text { Subcutaneous } & \text { Cattle } \\ \text { and } & \\ \text { Intramuscular } & \\ \text { Subcutaneous } & \begin{array}{l}\text { In vitro and } \\ \text { In vivo (Mice) }\end{array}\end{array}$

Subcutaneous Dog

Oral

In vitro

Subcutaneous Goat

Subcutaneous Rabbit

Intravenous Sheep

Subcutaneous Cattle

Subcutaneous Sheep

Topical

In vitro

Parenteral

In vitro

Implants

In vitro

Oral

Mice

Subcutaneous In vitro

Topical

Rat

Subcutaneous Rabbit 


\begin{tabular}{ll}
$\begin{array}{l}\text { Route of } \\
\text { administration }\end{array}$ & $\begin{array}{l}\text { Animal } \\
\text { understudy }\end{array}$ \\
\hline Transdermal & In vitro \\
Subcutaneous & $\begin{array}{l}\text { In vitro and } \\
\text { In vivo } \\
\text { (Wistar rats) }\end{array}$ \\
Subcutaneous & Rabbit
\end{tabular}

Ivermectin nanoemulsion (Cremophor EL ${ }^{\circledR}-35-26$ parts, Transcutol ${ }^{\circledR}$ HP - 12 parts, ethyl oleate -7 parts, ivermectin -2 parts, and water - 53 parts) was evaluated for transdermal drug delivery and was found to be stable and effective in transdermal delivery of ivermectin Nanocarriers for the delivery of ivermectin using lipid nanocapsules which are prepared by a new phase inversion procedure

Ivermectin-loaded Soy phosphatidylcholine-sodium deoxycholate mixed micelles were administered subcutaneously to improve the aqueous solubility of ivermectin. They produced less local irritation when compared to commercially available preparations

Sustained-release ivermectin-loaded solid lipid dispersion was prepared in a lipid matrix of hydrogenated castor oil and was administered subcutaneously

SLNs were used as a vehicle for transdermal delivery of ivermectin. The SLNs were produced by hot homogenization combined with the ultrasonic method

Sustained-release ivermectin varnish composed of $0.72 \mathrm{~g}$ of ivermectin, $3.6 \mathrm{~g}$ of amino methacrylate copolymer, $0.7 \mathrm{~g}$ of polyethylene glycol, and $2.15 \mathrm{~g}$ of hydroxypropyl cellulose per $100 \mathrm{ml}$ of absolute ethanol Sustained-release ivermectin-loaded solid dispersion suspension was formulated which was used in the therapeutic management of Psoroptes cuniculi infestation

Topical application of Palmitoyl-glycine-histidine gel spray formulations of ivermectin $(0.1 \%)$, which was prepared from its aqueous solution by a heating and cooling method

Ivermectin bolus formulation containing $8 \%$ microcrystalline cellulose, $0.5 \%$ starch, and $0.25 \%$ low-substituted hydroxypropyl cellulose produced sustained-release of the drug for more than 60 days

Ivermectin formulation containing self-emulsifying vehicles, such as sodium carboxymethylcellulose and poloxamers, was administered orally

Mixture of ivermectin and $\alpha$-Tocopherol-loaded microparticles based on poly-D, L-lactide or poly- $\varepsilon$-caprolactone together with sucrose and magnesium stearate were compressed to produce biodegradable subcutaneous implants

Transdermal release of ivermectin using self-implanted tiny needles of hyaluronic acid encapsulated with ivermectin-poly (lactic-co-glycolic acid) microparticles

\begin{tabular}{llc} 
Subcutaneous & Rabbit & {$[53]$} \\
Transdermal & In vitro & {$[54]$} \\
Topical & $\begin{array}{l}\text { Zoo-housed } \\
\text { animals }\end{array}$ & {$[55]$} \\
Subcutaneous & Rabbit & {$[56]$} \\
Topical & Rat & {$[57]$} \\
Oral & In vitro & {$[58]$} \\
Oral & Horse & {$[59]$} \\
Subcutaneous & In vitro & {$[60]$} \\
implant & & \\
Transdermal & $\begin{array}{l}\text { In vitro and } \\
\text { implant }\end{array}$ & In vivo (Rats) \\
\hline
\end{tabular}

$\mathrm{CR}=$ Covered-rod, $\mathrm{SLN}$ =Solid lipid nanoparticles, PLA=Poly $(\mathrm{D}, \mathrm{L}$-lactide $), \mathrm{PCL}=\mathrm{Poly}$ ( $\varepsilon$-caprolactone $)$

formulations of ivermectin. The current trends in developing ivermectin formulations are aimed toward reducing the number of doses of the therapeutic agent required for complete clinical cure of different parasitic diseases. Such formulations will also provide prophylactic concentrations of ivermectin in systemic circulation for a longer duration so that recurrence of such parasitic diseases would be unlikely despite repeated exposure. Single-dose therapeutic protocols for the management of infection and infestations are also becoming popular. These can be applied effectively in case of lipophilic molecules, such as avermectin group of drugs.

By altering the composition of oil-based vehicles used in ivermectin formulation, researchers can program its release at therapeutic concentrations continuously for a long period of time. Long-acting formulations have the advantage of reducing toxicity and such preparations can be used safely either in species which are sensitive to the drug or those drugs which have a lesser safety margin. Nevertheless, one must also be careful, since incompetent formulations may result in sub-therapeutic levels that can eventually induce ivermectin resistance.

\section{Author's Contributions}

KS and TSS conceptualized the review, collected the literature and prepared the manuscript. VAA studied and edited the manuscript. KD, AMP, and AP carried out the proof reading and finalized the manuscript and guided entirely during the preparation of this manuscript. All authors read and approved the final manuscript.

\section{Acknowledgments}

The authors are thankful to Director, ICARIndian Veterinary Research Institute, Bareilly, Uttar Pradesh, India for providing all the facilities.

\section{Competing Interests}

The authors declare that they have no competing interests. 


\section{Publisher's Note}

Veterinary World remains neutral with regard to jurisdictional claims in published institutional affiliation.

\section{References}

1. Ette, E.I., Thomas, W.O.A. and Achumba, J.I.,(1990) Ivermectin: A long-acting microfilaricidal agent. Ann. Pharmacother, 24(4): 426-433.

2. Gokbulut, C., Cirak, V.Y., Senlik, B., Aksit, D., Durmaz, M. and McKellar, Q.A.(2010) Comparative plasma disposition, bioavailability and efficacy of ivermectin following oral and pour-on administrations in horses. Vet. Parasitol., 170(1-2): 120-126.

3. Rang, H.P., Dale, M.M., Ritter, J.M. and Flower, R.J., editors.(2007) Rang and Dale's Pharmacology. $6^{\text {th }}$ ed. Churchill Livingstone, China. p715-716.

4. Atif, M., Estrada-Mondragon, A., Nguyen, B., Lynch, J.W. and Keramidas, A.(2017) Effects of glutamate and ivermectin on single glutamate-gated chloride channels of the parasitic nematode $H$. contortus. PLoS Pathog., 13(10): e1006663.

5. Lo,P.K.A., Fink, D.W.,Williams, J.B. and Blodinger,J.(1985) Pharmacokinetic studies of ivermectin: Effects of formulation. Vet. Res. Commun., 9(1): 251-268.

6. Shoop, W.L., Ostlind, D.A., Rohrer, S.P., Mickle, G., Haines, H.W., Michael, B.F. and Fisher, M.H.(1995) Avermectins and milbemycins against Fasciola hepatica: In vivo drug efficacy and in vitro receptor binding. Int. J. Parasitol., 25(8): 923-927.

7. Camargo, J.A., Sapin, A., Daloz, D. and Maincent, P.(2010) Ivermectin-loaded microparticles for parenteral sustained release: In vitro characterization and effect of some formulation variables. J. Microencapsul., 27(7): 609-617.

8. Geary, T.G.(2005) Ivermectin 20 years on: Maturation of a wonder drug. Trends Parasitol., 21(11): 530-532.

9. Etya'alé, D.(2002) Eliminating onchocerciasis as a public health problem: The beginning of the end. Br. J. Ophthalmol., 86(8): 844-846.

10. de Silva, N., Guyatt, H. and Bundy, D.(1997) Anthelmintics: A comparative review of their clinical pharmacology. Drugs, 53(5): 769-88.

11. Glaziou, P., Nyguyen, L.N., Moulia-Pelat, J.P., Cartel, J.L. and Martin, P.M.V.(1994). Efficacy of ivermectin for the treatment of head lice (Pediculosis capitis). Trop. Med. Parasitol., 45(3): 253-254.

12. Naquira, C., Jimenez, G., Guerra, J.G., Bernal, R., Nalin, D.R., Neu, D. and Aziz, M.(1989) Ivermectin for human strongyloidiasis and other intestinal helminths. Am. J. Trop. Med. Hyg., 40(3): 304-309.

13. Jacovella, J., Chappuis, J.P., Kaoukhov, A., Graeber, M., Poncet, M., Briantais, P., Salin, L. and Galderma, S.A.(2019) Treatment of Papulopustular Rosacea with Ivermectin. U.S. Patent Application, No. 10/206,939.

14. Wilkin, J., Dahl, M., Detmar, M., Drake, L., Feinstein, A., Odom, R. and Powell, F.(2002) Standard classification of rosacea: Report of the national rosacea society expert committee on the classification and staging of rosacea. $J$. Am. Acad. Dermatol., 46(4): 584-587.

15. Chaccour, C.J., Ngha'bi, K., Abizanda, G., Barrio, A.I., Aldaz, A., Okumu, F. and Killeen, G.(2018) Targeting cattle for malaria elimination: Marked reduction of Anopheles arabiensis survival for over six months using a slow-release ivermectin implant formulation. Parasit. Vectors, 11(1): 287.

16. Schaller, M., Gonser, L., Belge, K., Braunsdorf, C., Nordin, R., Scheu, A. and Borelli, C.(2017) Dual anti-inflammatory and anti-parasitic action of topical ivermectin 1\% in papulopustular rosacea. J. Eur. Acad. Dermatol. Venereol., 31(11): 1907-1911.
17. Ventre, E., Rozières, A., Lenief, V., Albert, F., Rossio, P., Laoubi, L. and Vial, E.(2017) Topical ivermectin improves allergic skin inflammation. Allergy, 72(8): 1212-1221.

18. Dominguez-Gomez, G., Chavez-Blanco, A., MedinaFranco, J.L., Saldivar-Gonzalez, F., Flores-Torrontegui, Y., Juarez, M. and Dueñas-González, A.(2018) Ivermectin as an inhibitor of cancer stem like cells. Mol. Med. Rep., 17(2): 3397-3403

19. Wang, J., Xu, Y., Wan, H. and Hu, J.(2018) Antibiotic ivermectin selectively induces apoptosis in chronic myeloid leukemia through inducing mitochondrial dysfunction and oxidative stress. Biochem. Biophys. Res. Commun., 497(1): 241-247.

20. Ajith, Y., Dimri, U., Gopalakrishnan, A. and Devi, G.(2019) A field study on the efficacy of ivermectin via subcutaneous route against chewing lice (Bovicola caprae) infestation in naturally infested goats. Onderstepoort J. Vet. Res., 86(1): $1-5$.

21. Wang, X., Lv, C., Ji, X., Wang, B., Qiu, L. and Yang, Z.(2019) Ivermectin treatment inhibits the replication of Porcine circovirus 2 (PCV2) in vitro and mitigates the impact of viral infection in piglets. Virus Res., 263: 80-86.

22. Paradies, P., Buonfrate, D., Iatta, R., Iarussi, F., Giorli, G., Palmieri, V.O. Sasanelli, M., Perandin, F., Šlapeta, J., Capogna, A., and Bisoffi, Z. and Otranto, D.(2019) Efficacy of ivermectin to control Strongyloides stercoralis infection in sheltered dogs. Acta Trop., 190: 204-209.

23. Sharun, K., Anjana, S., Sidhique, K. and Panikkassery, S.(2019) Treatment of sarcoptic mange infestation in rabbits with long acting injectable ivermectin. J. Parasit. Dis.,(2019): 1-4.

24. Pion, s.D., Tchatchueng-Mbougua, J.B., Chesnais, C.B., Kamgno,J.,Gardon,J.,Chippaux,J.P.andBoussinesq,M.(2019) Effect of a single standard dose $(150-200 \mu \mathrm{g} / \mathrm{kg})$ of ivermectin on Loa loa microfilaremia: Systematic review and meta-analysis. Open Forum Infect. Dis., 6(4): 1-18.

25. Canga, A.G., Prieto, A.M.S., Liebana, M.J.D., Martínez, N.F., Vega, M.S. and Vieitez, J.J.G.(2009) The pharmacokinetics and metabolism of ivermectin in domestic animal species. Vet. J., 179(1): 25-37.

26. Dong, J., Song, X., Lian, X., Fu, Y. and Gong, T.(2016) Subcutaneously injected ivermectin-loaded mixed micelles: Formulation, pharmacokinetics and local irritation study. Drug Deliv., 23(7): 2220-2227.

27. Frosch, P.J.(1995) Cutaneous irritation. In: Textbook of Contact Dermatitis Springer, Berlin, Heidelberg. p28-61.

28. Canga, A.G., Sahagun, A., Diez, M.J., Fernandez, N., Sierra, M. and Garcia, J.J.(2007) Bioavailability of a commercial formulation of ivermectin after subcutaneous administration to sheep. Am. J. Vet. Res., 68(1): 101-106.

29. Lifschitz, A., Sallovitz, J., Imperiale, F., Pis, A., Lorda, J.J. and Lanusse, C.(2004) Pharmacokinetic evaluation of four generic ivermectin formulations in calves. Vet. Parasitol., 119(2-3): 247-257.

30. Campbell, W.C.(2012) History of avermectin and ivermectin, with notes on the history of other macrocyclic lactone antiparasitic agents. Curr. Pharm. Biotechnol., 13(6): 853-865.

31. Houshaymi, B., Nasreddine, N., Kedees, M. and Soayfane, Z.(2019) Oleic acid increases uptake and decreases the P-gp-mediated efflux of the veterinary anthelmintic ivermectin. Drug Res., 69(3): 173-180.

32. Lo, P.K.A. and Williams, J.B.(1983) Solubilization of Ivermectin in Water. Merck and Co Inc., U.S. Patent, No. 4,389,397.

33. Herd, R.P., Sams, R.A. and Ashcraft, S.M.(1996) Persistence of ivermectin in plasma and feces following treatment of cows with ivermectin sustained-release, pour-on or injectable formulations. Int. J. Parasitol., 26(10): 1087-1093.

34. Gogolewski, R.P., Rugg, D., Allerton, G.R., Kawhia, D., Barrick, R.A. and Eagleson, J.S.(1997) Demonstration of 
the sustained anthelmintic activity of a controlled-release capsule formulation of ivermectin in ewes under field conditions in New Zealand. N. Z. Vet. J., 45(4): 163-166.

35. Bridi, A.A., Rehbein, S., Carvalho, L.A., Barth, D., Barrick, R.A. and Eagleson, J.S.(1998) Efficacy of ivermectin in a controlled release formulation against Psoroptes ovis (Hering, 1838) Gervais, 1841 (Acari: Psoroptidae) on sheep. Vet. Parasitol., 78(3): 215-221.

36. Rehbein, S., Corba, J., Pitt, S.R., Várady, M. and Langholff, W.K.(1999) Evaluation of the anthelmintic efficacy of an ivermectin controlled-release capsule in lambs under field conditions in Europe. Small Rumin. Res., 33(2): 123-129.

37. Lifschitz, A., Virkel, G., Pis, A., Imperiale, F., Sanchez, S., Alvarez, L. and Lanusse, C.(1999) Ivermectin disposition kinetics after subcutaneous and intramuscular administration of an oil-based formulation to cattle. Vet. Parasitol., 86(3): 203-215.

38. Maeda, H., Brandon, M. and Sano, A.(2003) Design of controlled-release formulation for ivermectin using silicone. Int. J. Pharm., 261(1-2): 9-19.

39. Clark, S.L., Crowley, A.J., Schmidt, P.G., Donoghue, A.R. and Piché, C.A.(2004) Long-term delivery of ivermectin by use of poly (D, L-lactic-co-glycolic) acid microparticles in dogs. Am. J. Vet. Res., 65(6): 752-757.

40. Liu, X., Sun, Q., Wang, H., Zhang, L. and Wang, J.Y.(2005) Microspheres of corn protein, zein, for an ivermectin drug delivery system. Biomaterials, 26(1): 109-115.

41. González, A., Sahagun, A.M., Diez, M.J., Fernandez, N., Sierra, M. and Garcia, J.J.(2006) Pharmacokinetics of a novel formulation of ivermectin after administration to goats. Am. J. Vet. Res., 67(2): 323-328.

42. Bassissi, F., Lespine, A. and Alvinerie, M.(2006) Assessment of a liposomal formulation of ivermectin in rabbit after a single subcutaneous administration. Parasitol. Res., 98(3): 244-249.

43. Lifschitz, A., Virkel, G., Ballent, M., Sallovitz, J., Imperiale, F., Pis, A. and Lanusse, C.(2007) Ivermectin (3.15\%) long-acting formulations in cattle: Absorption pattern and pharmacokinetic considerations. Vet. Parasitol., 147(3-4): 303-310.

44. Xu, F.R., Pan, B.L., Wang, Y.W., Pan, Z.D., Dai, X.X., Liu, P.H. and Wang, M.(2007) Pharmacokinetics of injectable long-acting ivermectin aqueous suspension following subcutaneous administration in sheep. J. Vet. Pharmacol. Ther, 30(5): 486-488.

45. Strycharz, J.P., Yoon, K.S. and Clark, J.M.(2008) A new ivermectin formulation topically kills permethrin-resistant human head lice (Anoplura: Pediculidae). J. Med. Entomol., 45(1): 75-81.

46. Camargo, J.A., Sapin, A., Nouvel, C., Daloz, D., Leonard, M., Bonneaux, F. and Maincent, P.(2013) Injectable PLA-based in situ forming implants for controlled release of ivermectin a BCS Class II drug: Solvent selection based on physicochemical characterization. Drug Dev. Ind. Pharm., 39(1): 146-155.

47. Yardley, M.M., Huynh, N., Rodgers, K.E., Alkana, R.L. and Davies, D.L.(2015) Oral delivery of ivermectin using a fast dissolving oral film: Implications for repurposing ivermectin as a pharmacotherapy for alcohol use disorder. Alcohol, 49(6): 553-559.

48. Dorati, R., Genta, I., Colzani, B., Tripodo, G. and Conti, B.(2015) Preliminary investigation on the design of biodegradable microparticles for ivermectin delivery: Set up of formulation parameters. Drug Dev. Ind. Pharm., 41(7): 1182-1192.

49. Miyajima, A., Komoda, M., Akagi, K., Yuzawa, K., Yoshimasu, T., Yamamoto, Y. and Hirota, T.(2015) Experimental study of pharmacokinetics of external, wholebody bathing application of ivermectin. J. Dermatol., 42(1): 87-89.

50. Chaccour, C., Barrio, Á.I., Royo, A.G.G., Urbistondo, D.M.,
Slater, H., Hammann, F., and Del Pozo, J.L.(2015) Screening for an ivermectin slow-release formulation suitable for malaria vector control. Malar. J., 14(1): 102.

51. Ding, D., Sheng, X.L., Liang, K.X., Xu, Q. and Liu, W.(2015) Study on ivermectin nanoemulsion for transdermal drug delivery. China Anim. Husbandry Vet. Med.,42(2): 401-407.

52. Gamboa, G.U., Palma, S.D., Lifschitz, A., Ballent, M., Lanusse, C., Passirani, C. and Allemandi, D.A.(2016) Ivermectin-loaded lipid nanocapsules: Toward the development of a new antiparasitic delivery system for veterinary applications. Parasitol. Res., 115(5): 1945-1953.

53. Lu, M., Xiong, D., Sun, W., Yu, T., Hu, Z., Ding, J. and Pan, B.(2017) Sustained release ivermectin-loaded solid lipid dispersion for subcutaneous delivery: In vitro and in vivo evaluation. Drug Deliv., 24(1): 622-631.

54. Guo, D., Dou, D., Li, X., Zhang, Q., Bhutto, Z.A. and Wang, L.(2018) Ivermectin-loaded solid lipid nanoparticles: Preparation, characterization, stability and transdermal behavior. Artif. Cells Nanomed. Biotechnol., 46(2): 255-262.

55. Avni-Magen, N., Eshar, D., Friedman, M., Kirmayer, D., Letschert, L., Gati, I. and Lavy, E.(2018) Retrospective evaluation of a novel sustained-release ivermectin varnish for treatment of wound myiasis in zoo-housed animals. J. Zoo Wildl. Med., 49(1): 201-205.

56. Lu, M., Cai, Y., Yang, S., Wan, Q. and Pan, B.(2018) A single subcutaneous administration of a sustained-release ivermectin suspension eliminates Psoroptes cuniculi infection in a rabbit farm. Drug Dev. Ind. Pharm., 44(12): 2000-2004.

57. Dahlizar, S., Futaki, M., Okada, A., Kadhum, W.R., Todo, H. and Sugibayashi, K.(2018) Design of a topically applied gel spray formulation with ivermectin using a novel low molecular weight gelling agent, palmitoyl-glycine-histidine, to treat scabies. Chem. Pharm. Bull., 66(3): 327-333.

58. Ruan, X., Gao, X., Gao, Y., Peng, L., Ji, H., Guo, D. and Jiang, S.(2018) Preparation and in vitro release kinetics of ivermectin sustained-release bolus optimized by response surface methodology. PeerJ, 6: e5418.

59. Lozina, L., Barbieri, F., Río, F., Bogado, E. and Ríos, E.(2018) Pharmaceutical development and clinical efficacy of ivermectin semisolid systems for oral administration in horses. Rev. Vet., 29(2): 93-97.

60. Dorati, R., Conti, B., Colzani, B., Dondi, D., Lazzaroni, S., Modena, T. and Genta, I.(2018) Ivermectin controlled release implants based on poly-D, 1-lactide and poly-e-caprolactone. J. Drug Deliv. Sci. Technol., 46: 101-110.

61. Chen, B.Z., Yang, Y., Wang, B.B., Ashfaq, M. and Guo, X.D.(2019) Self-implanted tiny needles as alternative to traditional parenteral administrations for controlled transdermal drug delivery. Int. J. Pharm., 556: 338-348.

62. Hennessy, D.R.(1997) Modifying the formulation or delivery mechanism to increase the activity of anthelmintic compounds. Vet. Parasitol., 72(3-4): 367-390.

63. Alvinerie, M., Sutra, J.F. and Galtier, P.(1993) Ivermectin in goat plasma and milk after subcutaneous injection. Vet. Res., 24(5): 417-421.

64. Eraslan, G., Kanbur, M., Liman, B.C., Çam, Y., Karabacak, M. and Altınordulu, Ş.(2010) Comparative pharmacokinetics of some injectable preparations containing ivermectin in dogs. Food Chem. Toxicol., 48(8-9): 2181-2185.

65. Alvinerie, M., Sutra, J.F., Galtier, P., Lifschitz, A., Virkel, G., Sallovitz, J. and Lanusse, C.(1999) Persistence of ivermectin in plasma and feces following administration of a sustained-release bolus to cattle. Res. Vet. Sci., 66(1): 57-61.

66. Atif, M., Smith, J.J., Estrada-Mondragon, A., Xiao, X., Salim, A.A., Capon, R.J. and Keramidas, A.(2019) GluClRmediated inhibitory postsynaptic currents reveal targets for ivermectin and potential mechanisms of ivermectin resistance. PLoS Pathog., 15(1): e1007570.

67. Doyle, S.R., Illingworth, C.J., Laing, R., Bartley, D.J., Redman, E., Martinelli, A. and Devaney, E.(2019) Population genomic and evolutionary modeling analyses reveal a single major QTL for ivermectin drug resistance 
in the pathogenic nematode, Haemonchus contortus. BMC Genomics, 20(1): 218.

68. Shoop, W.L.(1993) Ivermectin resistance. Parasitol. Today, 9(5): 154-159.

69. Xu, M., Molento, M., Blackhall, W., Ribeiro, P., Beech, R. and Prichard, R.(1998) Ivermectin resistance in nematodes may be caused by alteration of P-glycoprotein homolog. Mol. Biochem. Parasitol., 91(2): 327-335.

70. Lekimme, M., Farnir, F., Marechal, F. and Losson, B.(2010) Failure of injectable ivermectin to control psoroptic mange in cattle. Vet. Rec., 167(15): 575-576.

71. Wolstenholme, A.J., Evans, C.C., Jimenez, P.D. and Moorhead, A.R.(2015) The emergence of macrocyclic lactone resistance in the canine heartworm, Dirofilaria immitis. Parasitology, 142(10): 1249-1259.

72. Sangster, N.C. and Gill, J.(1999) Pharmacology of anthelmintic resistance. Parasitol. Today, 15(4): 141-146.

73. Currie, B.J., Harumal, P., McKinnon, M. and Walton, S.F.(2004) First documentation of in vivo and in vitro ivermectin resistance in Sarcoptes scabiei. Clin. Infect. Dis., 39(1): e8-e12.

74. Neodo, A., Schulz, J.D., Huwyler, J. and Keiser, J.(2019) In vitro and in vivo drug-drug interaction study of the effects of ivermectin and oxantel pamoate on tribendimidine. Antimicrob. Agents Chemother., 63(1): e762-18.

$* * * * * * * *$ 